\title{
Assessment of Readiness of Newly Graduated Health Professionals to Communicate with Patients in Duhok, Kurdistan Region, Iraq
}

\author{
Sirwan M. Aswad \\ Lecturer, Department of Family and Community Medicine, \\ College of Medicine, University of Duhok, Kurdistan Region, Iraq \\ Samim A. Al-Dabbagh \\ Professor and Chairman, Department of Family and Community Medicine, \\ College of Medicine, University of Duhok, Kurdistan Region, Iraq \\ Saad Y. Agha \\ Assistant Professor, Department of Family and Community Medicine, \\ College of Medicine, University of Duhok, Kurdistan Region, Iraq \\ Ghanim Y. Alsheikh* \\ WHO Collaborating Centre for Public Health Education \& Training, \\ Imperial College London, United Kingdom \\ Email: alsheikhg@gmail.com
}

\begin{abstract}
Communication Skills (CS) are essential to health workforce to conduct effective professional-patient interaction. In Iraq, majority of newly graduated health professionals are engaged in provision of direct health services. However, undergraduate curricula preparing these professionals include no distinct component to train them on CS. This study aims at assessing the status of CS among Health Professions Education (HPE) graduates of University of Duhok (UoD) and estimating the perception of their patients toward those skills. This cross-sectional study was conducted in 2014. Data on communication skills was obtained, from samples of different health professionals which included: medical doctors (junior residents, nurses, dentists and pharmacists) who recently graduated from different colleges at the UoD. Also, data from was obtained, their patients, to assess their satisfaction of the professionals' CS. For assessing core CS, a specially designed checklist was adopted from Calgary-Cambridge Guide. Also, senior clinicians were asked on CS performed by their junior residents. Results show that $88 \%$ of the senior academic staff regarded CS as "highly essential" and $66 \%$ of them were not satisfied with interns' conduct and suggested that CS should clearly be included in the medical curricula. The basic CS were perceived by patients as either not practiced or wrongly practiced. Patients were unsatisfied with the CS of their attending HPs during observed consultation sessions. The study shows obvious lack of CS among HPE graduates of UoD with patients' dissatisfaction of their CSs. It seems legitimate to propose that relevant training elements to be designed and incorporated within training modules are needed to realize as a core element of the curriculum of all HPE colleges at the UoD.
\end{abstract}

Keywords: Communication, skills, perception, graduates, Kurdistan-Iraq.

DOI: $10.7176 / \mathrm{JHMN} / 73-02$

Publication date: April $30^{\text {th }} 2020$

\section{Introduction}

The role of effective communication skills (CS) has widely been documented to alter several aspects of patient's health outcome and perception (Clever et al. 2008; Montini et al. 2008; Symons et al. 2009; Lienard et al. 2010; Boissy et all. 2016). However, the doctor-patient communication has been the focus with apparent ignorance regarding other health professionals apart from nurses and pharmacists (Bowles et al. 2001 and Majzub et al. 2010.) Furthermore, teaching and learning of CS has well been accepted as an essential component of medical education in the schools of medicine and other health sciences (Rider et al.2006 and Fiscella et al. 2007.) Besides, The World Health Organization has renewed its call for action in response to the need to equip graduates of health professions education with sound professional skill mix that includes CS (WHO, 2018.) The Regional Office of the World Health Organization has stressed importance of CS in the strategic framework for the development of health workforce for the years 2017-2030 to be followed by the region's countries (WHO 2018.) CSs have also been evidently identified in the sets of graduate outcomes of medical schools in USA (Joys et al. 2010) and in UK (Rajab and Al-Dabbagh 2011.)

Rajab and Al-Dabbagh (2011) indicated that in Kurdistan Region, as well as in most schools of health sciences 
in Iraq, no specific module for teaching and learning CS is adopted yet. This may be attributed to the currently implemented traditional model curriculum adopted by most of Iraqi schools (Al-Dabbagh and Al-Taee 2005.) Furthermore, Kurtz (2002) indicated that considerable difficulties face attempts to systematically integrate CS within current clinical training. Additionally, in Duhok, as in other Iraqi medical and nursing colleges, graduates are directly involved in providing health services upon graduation (Rajab \& Al-Dabbagh 2011.) Such situation demands planning for, and designing of, a relevant module/s for CS, which necessitates prior assessment of HPs and patient perception toward their skills. The "Calgary- Cambridge Guide on Teaching, and Learning Communication Skills in Medicine" was used in this study (Kurtz et al. 2005.) This work aims at assessing the status of CS practiced by newly graduated health professionals and working in Duhok health facilities, and, also estimating the perception of their patients and their senior clinicians toward those skills.

\section{Methods}

The study was conducted in Duhok, the capital city of Duhok Governorate which is one of the three governorates of the Iraqi Kurdistan Region, during 2014. The UoD is the main supplier of health care professionals in the governorate and houses the colleges of Medicine, Nursing, Pharmacy, Dentistry, and Health Sciences.

A cross-sectional design was adopted in the study and incorporated three parts. The first part was designed to assess the view of the senior clinicians towards their junior doctors' CS. The second part was designed to assess CS of newly graduated doctors, dentists, pharmacists and nurses, and the third part to assess patients' satisfaction and perception toward selected CS tasks practiced by their newly graduated caring health professionals.

The first part assessed the view of the clinical teaching staff at the College of Medicine towards CS in general. Duhok College of Medicine has adopted traditional subject-based and bedside teaching style since its establishment in 1992. A closed-ended self-administered questionnaire was distributed to a convenience sample of fifty clinical specialists regarding three main areas of CS. The first, eliciting their views and attitudes regarding the necessity of CS in clinical practice with three-answer options namely highly essential, fairly important or not very important in clinical practice. The second area is to asses specialists' satisfaction toward new graduate interns' CS using a two answer-options of either satisfied or not. The third area is to determine their suggestions to improve intern's CS and to choose one of the following options: introduce CS in the undergraduate medical curriculum, conduct postgraduate courses or introduce both options above.

The second part of the study was designed to assess CS of newly graduated doctors, dentists, pharmacists and nurses. The study settings comprised of: first, Azadi General Teaching Hospital (AGTH), which is the main secondary and the only tertiary care hospital in Duhok governorate, second, Duhok Emergency Teaching Hospital (DETH), and third, Duhok Dental Polyclinic. A timetable was designed to visit each health institution at a separate day each week. All the available staff that was on duty at the selected day was included in the study. A total of forty junior house officers, twenty pharmacists and thirty nurses were included from different clinical departments at AGTH and Emergency Reception ward of DETH; and twenty dentists working at Duhok Dental Polyclinic.

The assessment of clinical CS of these groups was done by a specially designed checklist with a 3-answer options: not attempted, partly performed or fully performed. This checklist was adopted from previous work designed and conducted as Calgary-Cambridge Guide (Kurtz 2005.) The checklist was reviewed by seven senior teaching members and some alterations were introduced to it. The checklist included basic tasks of general CS, questioning skills, listening skills and closure skills. A careful consideration was exerted to organization of these tasks to better address the total practice of different medical staff. One of the authors (SMA) conducted structured observation to score performance of a single HPs at one time who was given a standard 10 minutes long consultation session.

Finally, the third part of the study used a questionnaire developed to assess patient's satisfaction and perception toward selected CS tasks practiced by physicians, nurses, pharmacists and dentists working at the three settings mentioned above. In addition to the 3 settings stated above, seven PHCCs in Duhok were utilized in this part of the study which employ similar graduates. The questionnaire was composed of CS items included in the second part above and written in form of questions with 2-answer options: performed by HP or not. Data were obtained by direct interview conducted by member of the research team (SMA). All patients available at the time of the visit were interviewed after meeting with the attending doctors, dentists, nurses or pharmacists. A total of 320 patients were interviewed: 151 patients were interviewed in AGTH, 60 in DETH, 56 in (DDP) and 53 patients in the 3 (PHCCs.) The questionnaire was explained to all patients and all agreed to complete the questionnaire. Collected data were analyzed and presented in numbers and percentages.

\section{Results}

The study showed that, among the targeted 50 senior physicians, $88 \%$ (44) regarded CS as "highly essential" and $66 \%$ (33) were not satisfied with their interns' CS. Meanwhile, $80 \%$ (40) suggested inclusion of CS in the undergraduate medical curriculum plus conducting post-graduate training courses as means for improving interns' CS (table 1). 
The assessment of clinical communication skills (CCS) among the 40 newly graduated doctors (interns) showed that only one of the 16 CCS items was "fully performed" by $>50 \%$ of HP, 7 items were "partially performed" by $>50 \%$ of HP and 8 out of the 16 CCS items were "not attempted" by $>50 \%$ of HP observed.

Similarly, the assessment of CCS among the 30 newly graduated nurses showed that none of the 13 CCS items was "fully performed" by $>50 \%$ of HP, 4 items were "partially performed" by $>50 \%$ of HP and 8 out of the 13 CCS items were "not attempted" by $>50 \%$ of HP observed (table 2 a and b).

The assessment of clinical communication skills (CCS) among the 20 newly graduated dentists showed that two of the 13 CCS items was "fully performed" by $>50 \%$ of HP, 2 items were "partially performed" by $>50 \%$ of HP and 7 out of the 13 CCS items were "not attempted" by $>50 \%$ of HP observed. Similarly, the assessment of CCS among the 20 newly graduated pharmacists showed that four of the 7 CCS items was "fully performed" by $>50 \%$ of HP, 1 item was "partially performed" by $>50 \%$ of HP and only 2 out of the 7 CCS items were "not attempted" by $>50 \%$ of HP observed (table 3 a and b).

Table 4 shows the perception of patients towards CCS practiced by their attending interns, nurses, dentists or pharmacists. It reveals that $79 \%$ of patients admitted that their attending doctors had greeted them at the beginning of the session. It also shows that the vast majority of the patients were unsatisfied with their attending doctors' CS during consultation sessions; majority of patients (94\%) admitted that their interns did not close the session by summarizing the case for the patients. Small number of patients admitted they were honored privacy $(20 \%)$, introduced themselves and used patient's name (23\%), avoided interruption (23\%), explained procedures $(29 \%)$, offered a seat (36\%) or/and used understandable words (45\%).

Table 4 shows that $55 \%$ of patients were greeted by their attending dentist. However, low percentage of patients admitted that their attending dentists honored them privacy $(16 \%)$, avoided interrupting them while explaining their complaints $(22 \%)$, used their names $(38 \%)$, used understandable words $(45 \%)$, explained procedures (48\%) and summarized and provided follow up advice (48\%).

As for nurses, table 4 illustrates that three CCS tasks were performed by nurses and perceived positively in greeting the patient $(82 \%)$, honoring privacy $(81 \%)$, and using understandable words $(79 \%)$. Nurses did summarize and provided follow up advice to none of their patients in the sample $(0 \%)$. The other tasks were not performed by nurses to more than $50 \%$ of their patients in avoiding interrupting their patients (19\%), using their patients names $(36 \%)$, offering a seat $(39 \%)$ or in explaining procedures $(43 \%)$.

The majority of patients selected to provide their feedback on CS practiced by their pharmacists were unsatisfied with the five tested CCS tasks (table 4.) Only 4\% of patients admitted they received explanation on side effects of medicines, All other CS were perceived by minority of patients namely using patient's name (36\%), explain how to use medicines (43\%), greeting patient at beginning or and at end of contact (45\%) and in listening and answering questions (45\%).

\section{Discussion}

Several studies show strong positive association between healthcare provider's communication skills and several aspects of patient's health as related to compliance to treatment, improvement of patient satisfaction, establishment of positive patient-doctor relationship, proper health education, better diagnosis, self-management of chronic illness and adoption of proper preventive health behaviors ( Wong and Lee 2006; Montini et al. 2008; Boissy et al 2016; Rindlisbacher et al 2017.) Health care provider also achieves several paybacks being able of performing effective CSs including establishing doctor-patient rapport, improved self-efficacy and physician empathy, reduced physician burnout, more appropriate medical decisions and better health outcomes (Montini et al. 2008; Asnani 2009; Lienard et al. 2010; Raper et al.2015; Alofisan et al. 2016.) Health and medical education authorities in most of the countries are becoming more aware of the need to reform health systems and medical education. They face different priorities including preparing health professionals capable of providing the best possible care. To achieve such reform, World Health Organization has put colossal emphasis on competencies of CSs as one of five roles that a doctor, for example, should be able to perform side-to-side with being care provider, decision maker, community leader and manager (Boelen 1994.)

This study assessed the views of the health professions staff of UoD. About $66 \%$ of senior academic staff were not satisfied with interns' CSs, and $80 \%$ of them suggested to include CSs in the medical curriculum together with conducting post-graduate training courses as means for improving interns' CSs. A previous study completed in UoD College of Medicine revealed that interns lack problem-solving capabilities and interpersonal CSs. Also, the study showed that no formal CSs module exists in curriculum apart from only short, non-formal learning which is provided to medical students during their field training at the Department of Family and Community Medicine (Rajab and Al-Dabbagh 2011.)

The curriculum of health-related colleges at UoD follows the traditional subject-based and teaching-oriented module like most medical schools in Iraq and the neighboring countries. Problems existing within this model of curriculum include overcrowded and overrepresented syllabus with dissociation between basic and clinical sciences. Moreover, the knowledge domain is stressed at the expense of professional skills including CSs, where 
formal courses and components related to CSs and attitudes are not systematically covered (Al-Gindan et al. 2000; Rajab and Al-Dabbagh 2011.)

At one stage, a mere problem-based learning (PBL) was thought to be a better approach, at least for learning proper CSs. Studies done at the University of Tampere in Finland showed that the PBL method is no longer as well suited as during earlier phases (Wass et al. 2003.). In Japan, a study found that combining the PBL method with elements of Task-based learning (TBL) can be effective in focusing on the performance of tasks facing health care professionals in real life practice (Takahashi 2008.)

The study results found an obvious, and dominant, deficiency in practicing CSs among all four assessed health professions, namely, medical doctors, nurse, dentists and pharmacists (table 2). Almost all, except dentists, were graduates of UoD. The College of Dentistry has not yet graduated students at the time of the survey and almost all dentists were graduates from other dentistry colleges in Kurdistan, Iraq. The apparent poorly performed CSs observed could be attributed to lack of the CSs curriculum at those colleges, in addition to lack of any effective system for continuing professional development (CPD) to improve CSs across their career. Simonson (2013) emphasized the necessity to teach written and verbal communications to students and residents. The overload of patients and clinical work with shortage of staff and limited devoted to patients in local health facilities can be a serious cause for such deficiency in performing CSs.

The study demonstrated that the vast majority of patients were unsatisfied with CS practiced by their attending HP staff during consultation sessions. Some patients expressed their complaint about their doctor's failure to pursue a follow-up care because of their work overload. Similarly, in a study done in Lothian Hospitals Trust in Scotland, $60 \%$ of patients complained about a lack of involvement in decisions about their care, $33 \%$ said they were given no explanation of test results and $31 \%$ said they had no opportunity to talk to the doctor; $23 \%$ also complained of nurses and doctors saying different things (NHS/Scotland 2003.) Another study found that 17\% of complaints were due to poor provider-patient communication (Montini et al. 2008.) In Turkey, Ozdemir et al. (2013) reported a moderate mean score of communication skills among nurses. Similar results were found in Iran where patients were not highly satisfied with the CSs of their physicians (Narenjihan et al. 2012.)

On the other hand, dental students' self-perceived communication skills were found to increase patient motivation (Rindlisbacher et al. 2017.) Also, providing effective communication skills to nursing students was considered as a main goal of learning (Ghaffarifar et al. 2015.)

In the last three decades, there has been a significant increase in the number of medical, and other health sciences schools that offer formal communication skills courses (Simonson 2013.) Implementing such courses was thought to be essential in meeting the graduate competence and, at same time, achieve better patient satisfaction and ultimate health outcomes (Kurtz et al. 2005; Boissy et al. 2016.) The integration of CSs among other elements of the curriculum is seen as a better way to address the lack of formal CSs courses in a competency-based program setting. A study conducted in Tikrit medical college, Iraq, evaluating graduate's competencies from 6 Iraqi medical colleges showed that Tikrit graduates scored higher in the field of professional competencies. Communication skills form essential integrated element of Tikrit PBL curriculum and these skills are included in all parts of student's learning, and training and assessment activities along all the 6-year program (Alsheikh et al. 1999; Sulaiman \& Alsheikh 1995.) The World Health Organization has categorized medical skills into three domains: practical, communication and intellectual and stressed that in performance, and certainly, in learning-by-doing, these domains are intricately connected and performed together (Guilbert 1987.) Communication skills can be better acquired when students learn-by-doing these skills as integral part of learning process targeting graduate outcomes or competencies to cover the four stages of learning, training and assessing competencies namely: to know, to know how, to show how and to do as described by Miller (1990.)

\section{Conclusion}

The basic communication skills of the newly graduated health professionals, (medical doctors, nurses, dentists and pharmacists), were either not attempted at all or mostly practiced partially, and the majority of patients perceived these skills unsatisfactorily with their attending health professionals' communication skills during consultation sessions. There is an obvious need to implement appropriate training modules on communication skills, both distinct and integrated, in the curriculum of the four colleges of University of Duhok. Implementation of such training modules necessitates further periodic evaluative studies to assess the impact of such programs on the status of readiness of newly graduated health professionals to effectively communicate with their patients and to satisfy their expectation.

\section{References}

Al-Dabbagh, S.A., Al-Taee W.G. (2005), Evaluation of a Task-Based Community Oriented Teaching Model in Family Medicine for Undergraduate Medical Students in Iraq. BMC Medical Education, 5, 31. DOI: 10.1186/1472-6920-5-31

Al-Gindan, Y. M., Al-Sulaiman, A. A., Al-Faraidy, A. (2000). Undergraduate curriculum reform in Saudi medical 
schools. Which direction to go? Saudi Medical Journal, 21(4), 324-326. PMID: 11533810

Alofisan, T., Al-Alaiyan, S., Al-Abdulsalam, M., Siddiqui, K., Hussain, I.B., Al-Qahtani, M.H. (2016). Communication skills in pediatric training program: National-based survey of residents' perspectives in Saudi Arabia. Journal of Family and Community Medicine, 23(1):43-7. DOI: 10.4103/2230-8229.172233

Alsheikh, O.M., Hasson, A.F., Jasim, T.M., Mohammad, S.A., Mohammad, H.T., Al- Sumaidaie, M., ... Thanoun, N. N. (1999). Evaluation of medical graduates' performance from their seniors' point of view. Medical Journal of Tikrit University. 1999; 5,149-157. DOI: 10.13140/RG.2.1.4980.2969.

Asnani, M. R. (2009). Patient-physician communication. West Indian Medical Journal, 58(4): 357-361. PMID: 20099777

Boelen, C. The Five-Star Doctor: An asset to health care reform? Geneva, World Health Organization. 1994. DOI: https://www.who.int/hrh/en/HRDJ_1_1_02.pdf

Boissy, A., Windover, A.K., Bokar, D., Karafa, M., Neuendorf, K., Frankel, R.M., . . Rothberg, M. B. (2016). Communication Skills Training for Physicians Improves Patient Satisfaction. Journal of General Internal Medicine. 31(7):755-761. DOI: 10.1007/s11606-016-3597-2.

Bowles, N., Mackintosh, C., Torn, A. (2001). Nurses' communication skills: an evaluation of the impact of solution-focused communication training. Journal of Advanced Nursing. 36(3): 347-354. DOI: 10.1046/j.1365-2648.2001.01979.x.

Clever, S.L., Jin, L., Levinson, W., Meltzer, D.O. (2008). Does doctor-patient communication affect patient satisfaction with hospital care? Results of an analysis with a novel instrumental variable. Health Services Research. 43(5), 1505-1519. DOI: 10.1111/j.1475-6773.2008.00849.x.

Fiscella, K., Franks, P., Srinivasan, M., Kravitz, R.L., Epstein, R. (2007). Ratings of physician communication by real and standardized patients. Annals of Family Medicine, 5(2): 151-158. DOI: 10.1370/afm.643.

Ghaffarifar, S., Ghofranipour, F., Ahmadi, F., Khoshbaten, M. (2015). Why educators should apply theories and models of health education and health promotion to teach communication skills to nursing and medical students. Nursing and Midwifery Studies, 4(4): e29774. DOI: 10.17795/nmsjournal29774.

Guilbert, J.J. (1987). Educational handbook for health personnel. Genève, World Health Organization, WHO Offset Publication No. 35, 1.50-1.53. https://apps.who.int/iris/bitstream/handle/10665/42118/924170635X_eng.pdf?sequence=1\&isAllowed=y.

Joyce, B.L., Steenbergh, T., Scher, E. (2010). Use of the kalamazoo essential elements communication checklist (adapted) in an institutional interpersonal and communication skills curriculum. Journal of Graduate Medical Education, 2(2): 165-169. DOI: 10.4300/JGME-D-10-00024.1

Kurtz, S.M. (2002). Doctor-patient communication: principles and practices. Canadian Journal of Neurological Sciences, 29(S2): S23-S29. DOI: 10.1017/s0317167100001906

Kurtz, S., Silverman, J., Draper, J. (2005). Teaching, and learning communication skills in medicine. Oxford, Radcliffe Publishing. ISBN-10: 1857756584

Lienard, A., Merckaert, I., Libert, Y., Bragard, I., Delvaux, N., Etienne, A. M. . . Razavi, D. (2010). Transfer of communication skills to the workplace during clinical rounds: impact of a program for residents. PLoS One, 5(8), e12426. DOI: 10.1371/journal.pone.0012426.

Majzub, M.R., Rais, M.M., Jusoff, K. (2010). Communication skills of practicing pharmacists and pharmacy students. Studies in Sociology of Science, $1(1), \quad 67-72 . \quad$ DOI: http://www.cscanada.net/index.php/sss/article/view/j.sss.1923018420100101.007/1562.

Miller, G.E. (1990). The assessment of clinical skills/ competence/performance. Academic Medicine, 65(9), S63S67. DOI: 10.1097/00001888-199009000-00045

Montini, T., Noble, A.A., Stelfox, H.T. (2008). Content analysis of patient complaints. International Journal for Quality in Health Care, 20(6), 412-420. DOI: 10.1093/intqhe/mzn041.

Narenjiha, M., Haghighat, S., Bahaddor, H., Shajari, J., Jameie, S. B. (2012). The Importance of Physicians' Communication Skills and Patients' Satisfaction. Thrita Student Journal of Medical Sciences, 1(2), 57-61. DOI: $10.5812 /$ thrita.5460.

NHS/Scotland. Talking matters developing the communication skills of doctors. Edinburgh, Scottish goverment publications. ISBN: 0-7559-0919-0

Ozdemir, G., Kaya, H. (2013). Midwifery and nursing students' communication skills and life orientation: correlation with stress coping approaches. Nursing and Midwifery Studies, 2(2), 198-205. PMID: 25414859.

Rajab, A.J., Al-Dabbagh, S.A. (2011). The role of short intensive task based learning course in improving emergency medicine performance among interns in Duhok, Kurdistan Region, Iraq. Duhok Medical Journal, 5(1), 1-14. DOI: https://www.iasj.net/iasj?func=fulltext\&aId=160447

Raper, S.E., Gupta, M., Okusanya, O., Morris, J.B. (2015). Improving communication skills: A course for academic medical center surgery residents and faculty. Journal of Surgical Education, 72(6), e202-e211. DOI: 10.1016/j.jsurg.2015.06.008

Rider, E.A., Hinrichs, M.M., Lown, B.A. (2006). A model for communication skills assessment across the 
undergraduate curriculum. Medical Teacher, 28(5): 127-134. PMID: 16973446.

Rindlisbacher, F., Davis, J.M., Ramseier, C.A. (2016). Dental students' self-perceived communication skills for patient motivation. European Journal of Dental Education, 21(3), 166-174. DOI: 10.1111/eje.12196.

Simonson, J.A. (2013). Why we must teach written and verbal communication skills to medical students and residents. Academic Medicine, 88(4):435. DOI: 10.1097/ACM.0b013e3182854f57.

Sulaiman, N.D., Alsheikh, G.Y. (1995). The fully integrated problem based medical curriculum: experience in Tikrit University College of Medicine. Yemen Medical Journal, 1(1), 78-82. DOI: $10.13140 /$ RG.2.1.3990.6000

Symons, A.B., Swanson, A., McGuigan, D., Orrange, S., Akl, E.A. (2009). A tool for self-assessment of communication skills and professionalism in residents. BMC Medical Education. 9:1. DOI: 10.1186/14726920-9-1.

Takahashi, Y. (2008). Problem-based learning and task-based learning: a practical synthesis. Kaohsiung Journal of Medical Sciences, 24(3 Suppl), S31-S33. DOI: 10.1016/s1607-551x(08)70091-3

Wass, V., Richards, T., Cantillon, P. (2003). Monitoring the medical education revolution. British Medical Journal, 327(7428): 1362. DOI: 10.1136/bmj.327.7428.1362

Wong, S.Y., Lee, A. (2006). Communication skills and doctor-patient relationship. Medical Bulletin, 11(3), 7-9. http://www.fmshk.org/database/articles/607.

World Health Organization. (2018). Framework for action for health workforce development in the Eastern Mediterranean Region 2017-2030. Cairo, Regional Office for the Eastern Mediterranean, WHOEM/HRH/640/E. http://applications.emro.who.int/docs/EMROPub_2018_EN_20314.pdf

Table No. 1. Attitude, Satisfaction and Suggestions of senior clinicians toward their Interns' CCSs ( $=50)$

\begin{tabular}{|l|l|c|}
\hline \multirow{2}{*}{ Attitude, satisfaction, and suggestions toward interns' CSs } & No. (\%) \\
\hline \multirow{3}{*}{ Importance } & Highly essential & $44(88)$ \\
\cline { 2 - 3 } & Fairly important & $6(12)$ \\
\cline { 2 - 3 } Satisfaction & Not important & $0(0)$ \\
\hline \multirow{3}{*}{ Improvement suggestions } & Satisfied & $17(34)$ \\
\cline { 2 - 3 } & Not satisfied & $33(66)$ \\
\cline { 2 - 3 } & Include CS in the medical curriculum & $4(8)$ \\
\cline { 2 - 3 } & Conduct post-graduate training courses & $6(12)$ \\
\cline { 2 - 3 } & Both of above & $40(80)$ \\
\hline
\end{tabular}

Table No. 2. Assessment of CCSs among newly graduated interns (a) and nurses (b).

\begin{tabular}{|c|c|c|c|}
\hline \multicolumn{4}{|c|}{ a. Assessments of Intern's CCSs $(n=40)$} \\
\hline CCS tasks & $\begin{array}{c}\text { Not } \\
\text { attempted } \\
\text { No. }(\%) \\
\end{array}$ & $\begin{array}{c}\text { Partially } \\
\text { performed } \\
\text { No. (\%) } \\
\end{array}$ & $\begin{array}{c}\text { Fully performed } \\
\text { No. }(\%)\end{array}$ \\
\hline Greeting and using patient name & $34(85)$ & $6(15)$ & $0(0)$ \\
\hline Self-introduction/explain purpose & $40(100)$ & $0(0)$ & $0(0)$ \\
\hline Obtaining consent & $39(97)$ & $1(3)$ & $0(0)$ \\
\hline Using nonverbal CS & $4(10)$ & $35(87)$ & $1(3)$ \\
\hline Position and posture & $6(15)$ & $33(83)$ & $1(3)$ \\
\hline Using open questions & $10(25)$ & $30(75)$ & $0(0)$ \\
\hline Avoidance of jargons & $3(8)$ & $3(8)$ & $34(84)$ \\
\hline Avoidance of interruption & $24(60)$ & $14(35)$ & $2(5)$ \\
\hline Avoidance of directing & $13(33)$ & $26(64)$ & $1(3)$ \\
\hline Clarification of patient talk & $12(30)$ & $25(62)$ & $3(8)$ \\
\hline Using the patient name frequently & $28(70)$ & $12(30)$ & $0(0)$ \\
\hline Privacy & $40(100)$ & $0(0)$ & $0(0)$ \\
\hline Timing the interview & $24(60)$ & $16(40)$ & $0(0)$ \\
\hline Clear speech & $9(23)$ & $23(57)$ & $8(20)$ \\
\hline Asking anything else & $28(70)$ & $8(27)$ & $1(3)$ \\
\hline \multicolumn{4}{|c|}{ b. Assessment of Nurse's CCSs $(n=30)$. } \\
\hline CCS tasks & $\begin{array}{c}\text { Not } \\
\text { attempted } \\
\text { No. }(\%) \\
\end{array}$ & $\begin{array}{c}\text { Partially } \\
\text { performed } \\
\text { No. (\%) } \\
\end{array}$ & $\begin{array}{c}\text { Fully performed } \\
\text { No. }(\%)\end{array}$ \\
\hline Greeting and using patient name & $25(84)$ & $5(16)$ & $0(0)$ \\
\hline
\end{tabular}




\begin{tabular}{|l|c|c|c|}
\hline Self-introduction/explain purpose & $28(93)$ & $2(7)$ & $0(0)$ \\
\hline Obtaining consent & $23(77)$ & $7(23)$ & $0(0)$ \\
\hline Using nonverbal CS & $16(53)$ & $14(47)$ & $0(0)$ \\
\hline Avoidance of jargons & $4(13)$ & $26(87)$ & $0(0)$ \\
\hline Avoidance of interruption & $21(70)$ & $9(30)$ & $0(0)$ \\
\hline Using the patient name frequently & $30(100)$ & $0(0)$ & $0(0)$ \\
\hline Privacy & $15(50)$ & $15(50)$ & $0(0)$ \\
\hline Timing the interview & $30(100)$ & $0(0)$ & $0(0)$ \\
\hline Management of pain & - & $28(97)$ & $1(3)$ \\
\hline Asking anything else & $13(43$ & $17(57)$ & $0(0)$ \\
\hline
\end{tabular}

Table No. 3. Assessment of CCSs among newly graduated dentists (a) and pharmacists (b)

\begin{tabular}{|c|c|c|c|}
\hline \multicolumn{4}{|l|}{ a. Assessment of Dentist's CCSs $(n=20)$. } \\
\hline $\begin{array}{l}\text { CCS tasks attempted or not by number ( } \%) \\
\text { of Dentists }\end{array}$ & $\begin{array}{c}\text { Not } \\
\text { attempted } \\
\text { No. }(\%)\end{array}$ & $\begin{array}{l}\text { Partially performed } \\
\text { No. }(\%)\end{array}$ & $\begin{array}{l}\text { Fully performed } \\
\text { No. }(\%)\end{array}$ \\
\hline Greeting and using patient name & $11(55)$ & $9(45)$ & $0(0)$ \\
\hline Self-introduction/explain purpose & $18(90)$ & $2(10)$ & $0(0)$ \\
\hline Obtaining consent & $18(90)$ & $2(10)$ & $0(0)$ \\
\hline Using nonverbal CS & $4(20)$ & $16(80)$ & $0(0)$ \\
\hline Avoidance of jargons & $1(5)$ & $0(0)$ & $19(95)$ \\
\hline Avoidance of interruption & $15(75)$ & $1(5)$ & $4(20)$ \\
\hline Using the patient name frequently & $15(75)$ & $5(25)$ & $0(0)$ \\
\hline Privacy & $19(95)$ & $1(5)$ & $0(0)$ \\
\hline Timing the interview & $9(45)$ & $9(45)$ & $2(10)$ \\
\hline Management of pain & $7(35)$ & $9(45)$ & $4(20)$ \\
\hline Asking anything else & $16(80)$ & $4(20)$ & $0(0)$ \\
\hline Confidentiality & $8(40)$ & $8(40)$ & $4(20)$ \\
\hline Adhering to truth & $2(10)$ & $12(60)$ & $6(30)$ \\
\hline \multicolumn{4}{|l|}{ b. Assessment of Pharmacists' CCSs $(\mathrm{n}=20)$} \\
\hline $\begin{array}{l}\text { CCS tasks attempted or not by number (\%) } \\
\text { of Pharmacists }\end{array}$ & $\begin{array}{l}\text { Not attempted } \\
\text { No, }(\%)\end{array}$ & $\begin{array}{l}\text { Partially performed } \\
\text { No, }(\%) \\
\end{array}$ & $\begin{array}{l}\text { Fully performed } \\
\text { No, }(\%)\end{array}$ \\
\hline Using patient name frequently & $0(0)$ & $7(35)$ & $13(65)$ \\
\hline Explain how to take medicine & $0(0)$ & $7(35)$ & $13(65)$ \\
\hline Explain adverse effects of medicine & $10(50)$ & $7(35)$ & $3(15)$ \\
\hline Using nonverbal CS & $6(30)$ & $14(70)$ & $0(0)$ \\
\hline Avoidance of jargons & $0(0)$ & $1(5)$ & $19(95)$ \\
\hline Avoidance of interruption & $12(60)$ & $6(30)$ & $2(10)$ \\
\hline Deal with one patient at a time & $3(15)$ & $0(0)$ & $17(85)$ \\
\hline
\end{tabular}

Table No. 4. Number and percentage of patients' who perceived CCSs practiced by Interns, Dentists, Nurses and Pharmacists.

\begin{tabular}{|l|c|c|c|c|}
\hline $\begin{array}{l}\text { CCS tasks perceived as "not performed" by } \\
\text { number }(\%) \text { of patients }\end{array}$ & $\begin{array}{c}\text { Interns } \\
(\mathrm{n}=151) \\
\text { No. }(\%)\end{array}$ & $\begin{array}{c}\text { Dentists } \\
(\mathrm{n}=60) \\
\text { No. }(\%)\end{array}$ & $\begin{array}{c}\text { Nurses } \\
(\mathrm{n}=56) \\
\text { No. }(\%)\end{array}$ & $\begin{array}{c}\text { Pharmacists } \\
(\mathrm{n}=53) \\
\text { No. }(\%)\end{array}$ \\
\hline Greeting & $102(79)$ & $33(55)$ & $46(82)$ & $24(45)$ \\
\hline Using patient name & $35(23)$ & $23(38)$ & $20(36)$ & $19(36)$ \\
\hline Asking to sit & $54(36)$ & NA & $22(39)$ & NA \\
\hline Avoidance of interruption & $35(23)$ & $13(22)$ & $10(19)$ & NA \\
\hline Explain procedure/s & $43(29)$ & $29(48)$ & $24(43)$ & NA \\
\hline Privacy & $31(20)$ & $13(16)$ & $45(81)$ & NA \\
\hline Using understandable words & $68(45)$ & $30(45)$ & $44(79)$ & NA \\
\hline Summarizing/follow up advices & $9(6)$ & $29(48)$ & $0(0)$ & NA \\
\hline Explain how to take medicine & NA & NA & NA & $23(43)$ \\
\hline Listening and answering Qs. & NA & NA & NA & $24(45)$ \\
\hline Explain side effect of medicine & NA & NA & NA & $2(4)$ \\
\hline
\end{tabular}

